\title{
Features of psychological mechanisms of self- regulation among students of different professional orientation
}

\author{
Anna Kukulyar $^{1}$, Anastasia Kolenova ${ }^{1, *}$, Yulia Karagodskaya $^{1}$, Anna Kryuchkova ${ }^{1}$, and \\ Viktoria Korhova ${ }^{1}$ \\ ${ }^{1}$ Don State Technical University, 344003 Rostov-on-Don, Russian Federation, Gagarin sq.1
}

\begin{abstract}
The modern social environment in general, and educational in particular, imposes a number of requirements on the personality of the student as a future representative of the professional community. This manifests itself in the need to master professional knowledge and skills in the conditions of constantly changing requirements, planning their activities for the short and / or long term, as well as multiple flexibility of behavior. The object of the research was 100 students of various faculties of DSTU (technical and humanitarian orientation). In the course of the empirical study, we used diagnostic methods for identifying self-regulation mechanisms in the student environment "USK" by J. Rotter; a questionnaire for the diagnosis of individual stylistic features of selfregulation (V. I. Morosanova), the methodology "Research of volitional self-regulation" (A. V. Zverkova, E. V. Eydman). The practical significance of the work lies in the subsequent use of the data obtained in the framework of psychocorrectional work with students of the organization of secondary vocational education.
\end{abstract}

\section{Introduction}

Self-regulation is a personality quality that contributes to the organization of activities and the productivity of achieving goals. At the same time, the formation of self-regulation is reflected in all types of personality activities. Self-regulation occurs at several stages of activity, without which a high level of regulation can have the opposite effect. In this regard, the study of the awareness of self-regulation acquires importance.

Self-regulation, as a research problem, is presented in the works of such domestic scientists as V.I. Morosanova, O. A. Konopkin, A. G. Dikaya, A. K. Osnitsky and others [1-16]. They consider self-regulation as a complex characteristic that contributes to the advancement of a goal of activity, adherence to a plan to achieve it and the possibility of varying the means of activity.

In domestic science, it is customary to subdivide self-regulation on the basis of what acts as an object: a state, behavior or activity. Empirical studies presented in the literature allow to form a basic understanding of self-regulation.

\footnotetext{
* Corresponding author: kolenova.nastya@ya.ru
} 
The applied aspect of the study of self-regulation is mostly represented in foreign studies and is associated with the names of five researchers: R. Baumeister, M. Gailliot, M. Oaten, P. Carolay (Karoly), J. Carver ( Carver) and others [1- 5, 10, 13].

Studies of conscious self-regulation as a quality, the appeal to which has a situational character and occurs at the initial stages of organizing activities in the event of difficulties in achieving the goal, are presented in the works of O. A. Konopkin, V. E. Klochko, E. A. Medovikova [4-9, 12, 15, 17]. Cognitive styles reflect the peculiarities of the perception and processing of information in general, as well as that which is necessary when organizing activities.

\section{Discussion}

Today, self-regulation is the subject of study of various sciences, such as sociology, economics, biology, psychology, etc. It all depends on the systems considered by science. In this master's thesis, we will consider self-regulation from the point of view of psychological sciences. So, the term self-regulation is understood as the ability of various systems to maintain internal stability at a constant level, despite external influences. Many scientists associate the problem of naming this phenomenon with a varied approach to describing the theoretical basis and, of course, with the lack of a generally accepted approach to studying the stated problem. As mentioned earlier, in modern approaches to the study of self-regulation, in most cases, a certain combination of the subject's needs, included by logic, with the process of choosing an action is understood.

In addition, it is endowed with a controlling power to ensure victorious reactions. Despite this, there is still no definiteness in terminology when asked about self-regulation, the consistency of understanding its structure. So far, we can talk about this definition only as an explanatory concept, which in a small part is able to clarify the mechanisms of human actions, the basis of which are not only desires, but also decisions aimed at the result of the individual. During the history of the existence of this term, experimental studies were carried out more than once, which were supposed to become the basis for understanding the phenomenon.

For university students, such personality traits, which are characteristic of the adolescent period, are important. Despite the fact that the problem of professional selfdetermination was solved by them before the start of training, the difficulties associated with this, as well as secondary professional self-determination, continue to influence the development of students. This is manifested in the formation of professional identity, the construction of life plans and the crisis of youth.

\section{Research methods and techniques}

Diagnostic methods for the peculiarities of the functioning of self-regulation mechanisms in the student environment "USK" by J. Rotter; a questionnaire for diagnostics of individual stylistic features of self-regulation (V. I. Morosanova) [17], a methodology "Research of volitional self-regulation" (A. V. Zverkova, E. V. Eydman) [13]. As well as methods for processing empirical results: qualitative methods, content analysis, methods of mathematical statistics.

The object of the research was 100 students of various faculties of DSTU (technical and humanitarian orientation).

\section{Research results}


We have determined the level of students' subjective control by the method of J. Rotter. The data obtained from the results of each of the 7 scales are presented below in Figure 1.

In the course of the analysis of empirical data, it can be concluded that among the entire sample of respondents, $83 \%$ of engineering students and $21 \%$ of humanities students have an internal locus of control. An external locus of control is possessed by $79 \%$ of humanities students and $17 \%$ of engineering students.

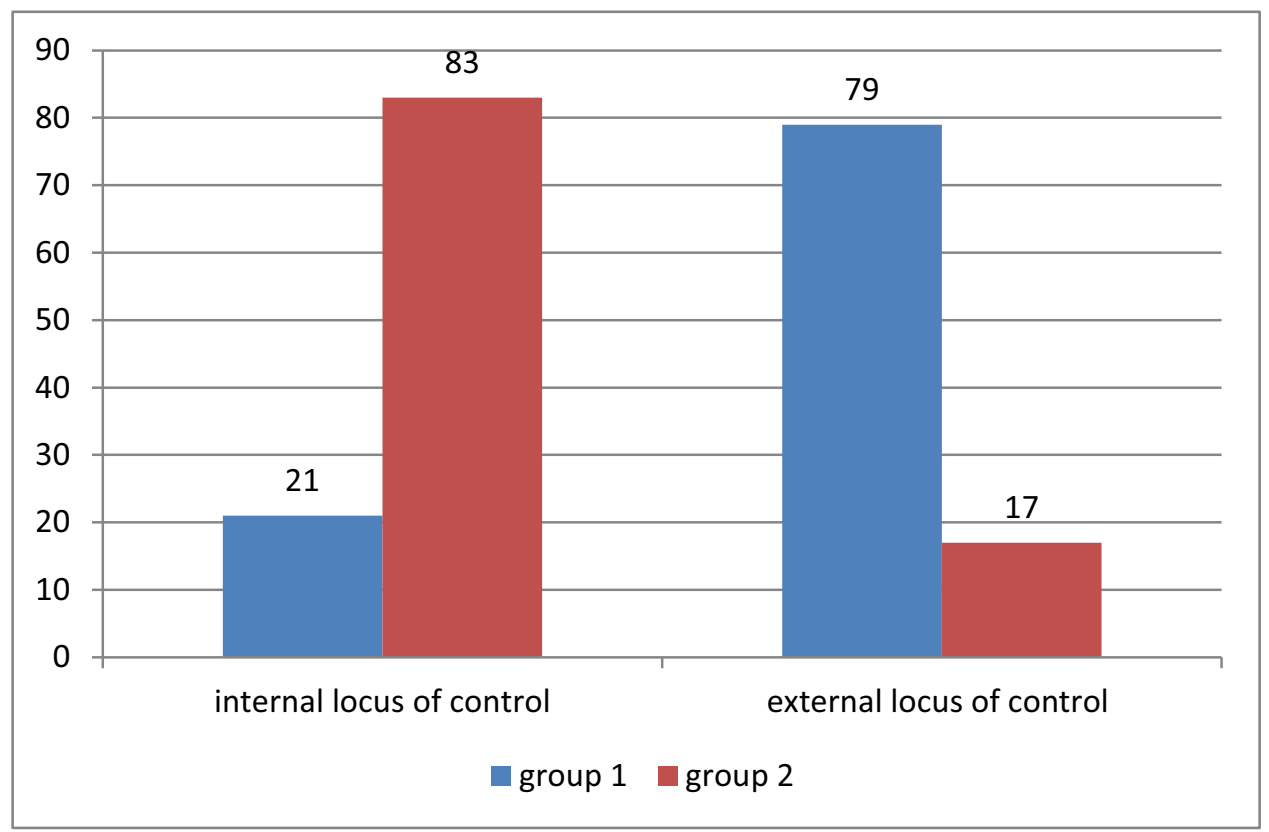

Fig. 1. Features of the level of subjective control of students (\%)

Thus, we can conclude that among students of the 1st group (humanities), external LC prevails, on the basis of which they tend to rely on their experience, qualifications, competence and level of abilities when achieving the desired result of purposeful activity and initiative. They are characterized by higher cognitive activity, which allows them to encompass past and present events to predict future behavior strategies. Their behavior is characterized by the gradual achievement of success, by improving skills and detailed processing of information coming from outside, as well as the gradual formation of tasks in terms of their complexity. Although, they have less resistance to stress in situations of serious failure, according to J. Rotter.

Among the students of group 2 (engineering), the internal locus of control prevails, they are characterized by externally directed defensive behavior, in any situation they expect to have a chance of success, but they also pay tribute to the factors that are not dependent on them. They treat the failures lightly and do not take them personally. Often, they need support and approval, perceiving them as happening by themselves.

Next, we present the results regarding two groups of respondents according to 7 scales of the methodology by J. Rotter, which are presented below in Figure 2. 


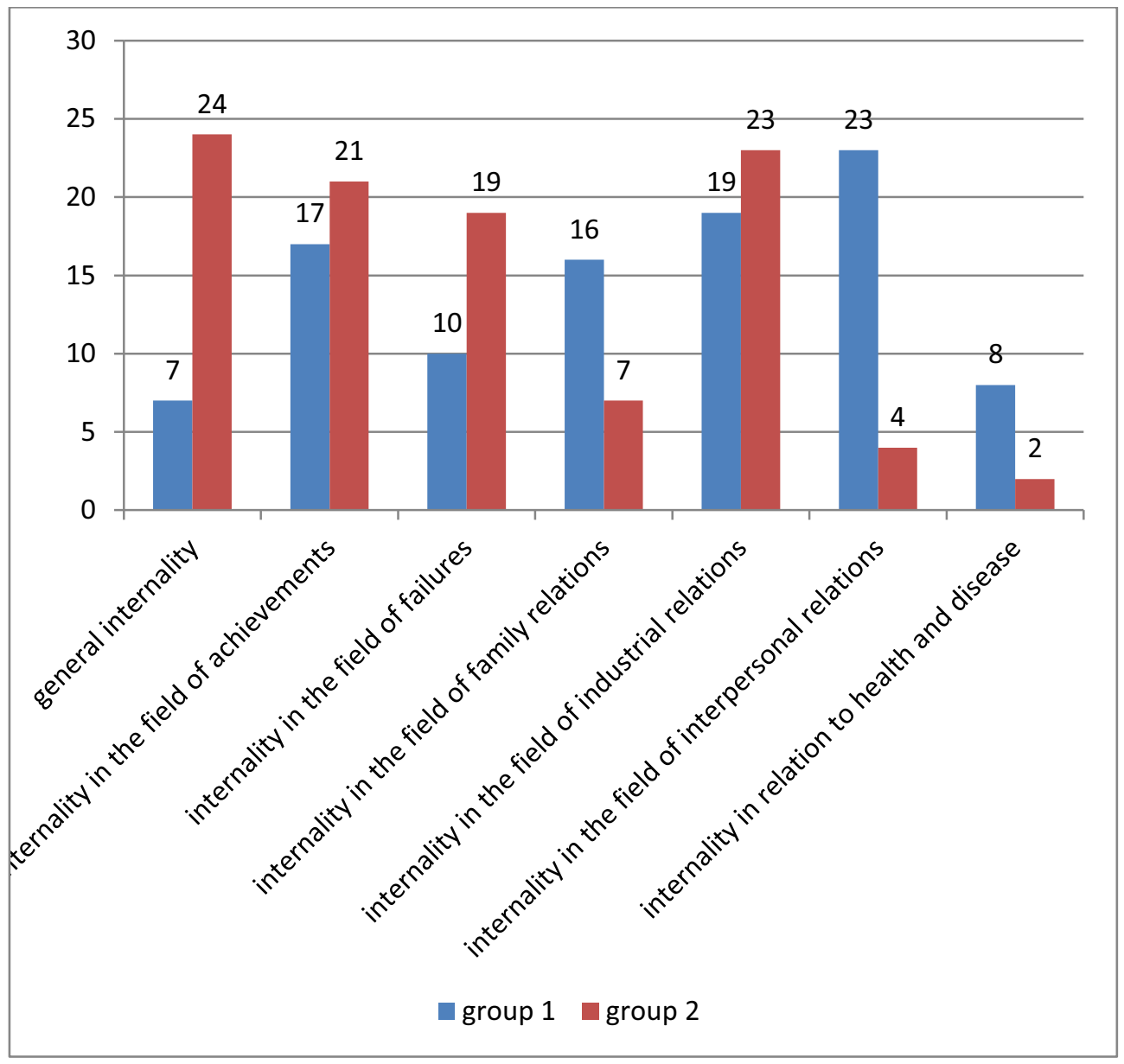

Fig. 2. Distribution of internality levels among the entire sample of students (\%)

Interpreting the data obtained, we can conclude that among the group of humanitarian orientation (group 1) a high level of internality prevails in the field of interpersonal relations $(23 \%)$, industrial relations $(19 \%)$, achievements $(17 \%)$ and family relations $(16 \%)$, which indicates about the desire to actively form their circle of friends, the formation of active interpersonal relationships, the desire to control their formal and informal relationships with other people, organize their own production relations, regulate relationships within the team and groups, independently control various emotional events and situations. With regard to family relationships, they consider themselves responsible for most of the events that occur.

In group 2 (engineering), a high level of internality prevails in the following areas: the general level of internality (24\%), industrial relations (23\%), achievements $(21 \%)$, failures $(19 \%)$, which in most indicators is similar to the level of internality in group 1, but at the same time there is a specific severity of some indicators (Io and In). The general level of internality reflects the desire of engineering students to regularly monitor most of the events that occur and feel responsible for them, while they tend to blame themselves for various troubles and suffering.

Low values in 2 groups of students were achieved by indicators on the Iz scale $(12 \%$ humanities and $18 \%$ - engineering), which emphasizes the general tendency to low control of their own health. 
The data obtained in the course of the study on all scales of the "USC" methodology by J. Rotter between humanities and engineering students confirm statistically significant differences according to Student's t-test, where differences are considered significant at $\mathrm{p} \geq$ 0.01-0.05. The results of the statistical analysis are presented below in Table 1 .

Table 1. Results of statistically significant differences between the averaged data on the USC Rotter scales among humanities and engineering students

\begin{tabular}{|l|l|l|l|}
\hline Scales & $\begin{array}{l}\text { Humanities } \\
\text { students }\end{array}$ & $\begin{array}{l}\text { Engineering } \\
\text { students }\end{array}$ & significance level (p-value) \\
\hline Io & 22.3 & 36.8 & 0.0406 \\
\hline Id & 10.4 & 10.8 & 0.0340 \\
\hline In & 8.3 & 3.2 & 0.0629 \\
\hline Ic & 7.2 & 5.1 & 0.07649 \\
\hline Ip & 8.4 & 8.6 & 0.0115 \\
\hline Im & 3.9 & 1.3 & 0.03228 \\
\hline Iz & 1.4 & 0.8 & 0.0495 \\
\hline
\end{tabular}

Based on the conducted statistical analysis, it can be concluded that the hypothesis that there are probably differences in the functioning of self-regulation mechanisms among students of different professional orientations has been partially confirmed.

At the next stage of work, we analyzed the styles of self-regulation among students of various specialties according to the method of V.I. Morosanova. The data obtained are presented below in Figure 3.

Among the group of humanitarians (group 1), the leading is the General level of selfregulation $(87 \%)$, which indicates a high awareness and interconnectedness in the general structure of individual regulation of regulatory links, which characterizes them as independent, flexible and adequately responding to changes in conditions, promotion and achievements of goals. With high achievement motivation, they are able to form a style of self-regulation that allows them to compensate the influence of personal, characterological characteristics that impede the achievement of the goal. The higher the general level of conscious self-regulation, the easier a person masters new types of activity, the more confident he feels in unfamiliar situations, the more stable his success in usual activities. 


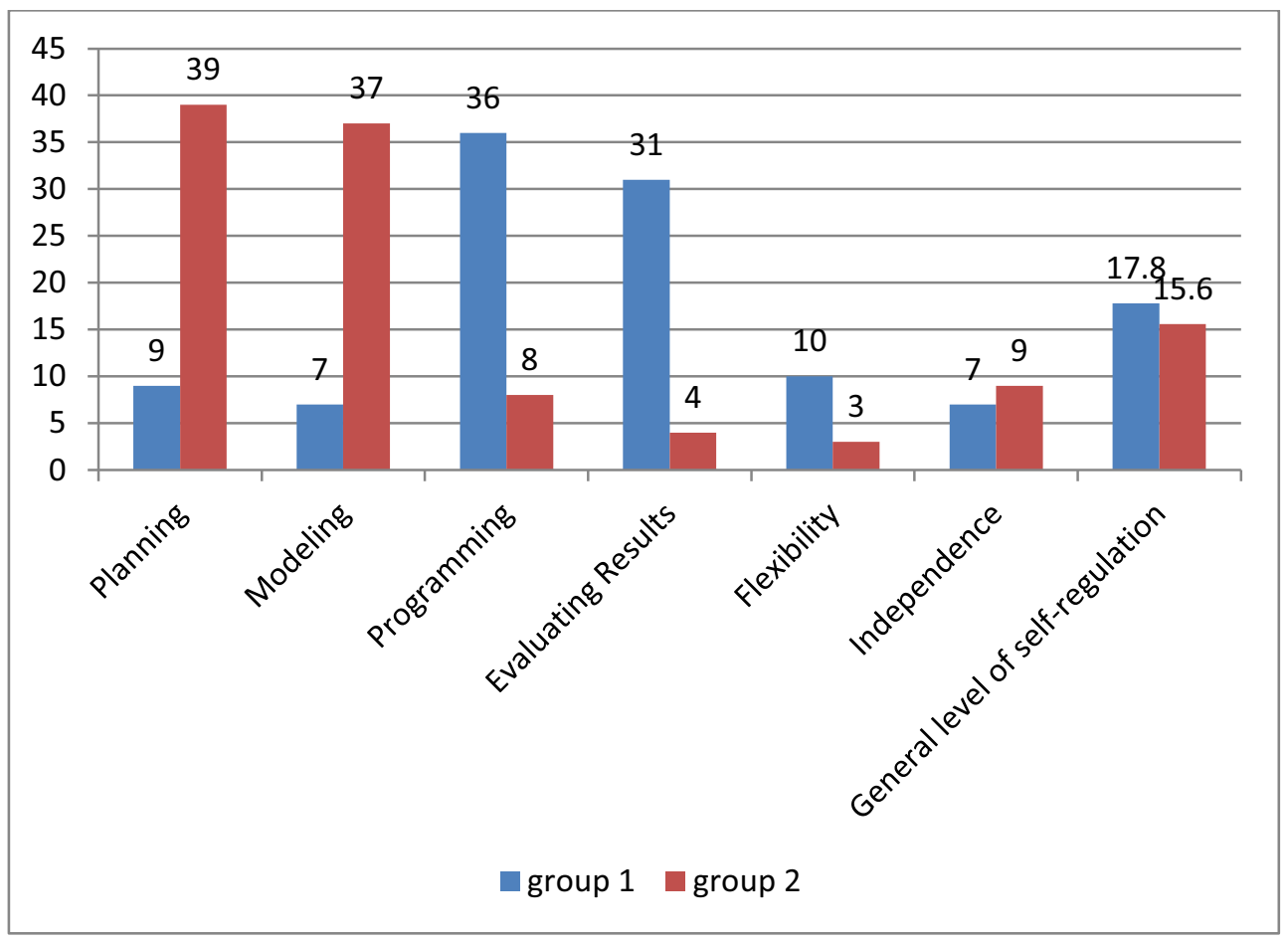

Fig. 3. The prevalence of regulation styles among the entire sample of students (\%)

The indicator on the scale of "Programming" (36\%) and "Evaluation of results" (31\%) also reached high values among humanities students, which reflects their desire to plan further actions and results, ready to adapt to changing life circumstances. They adequately assess the mismatch between the goals of the activity and the results obtained.

Among the group of engineering students (group 2), the leading styles of self-regulation are "Planning" (39\%) and "Modeling" (37\%), which indicates the formation of the need for conscious planning of activities, the plans in this case are realistic, detailed, hierarchical and stable, the goals of the activity are put forward independently by these students. They are also able to highlight the significant conditions for achieving goals, both in the current situation and in the long-term future, which is manifested in the compliance of action programs with action plans, the compliance of the results obtained with the adopted goals.

The minimum values were diagnosed only in group 2 on the scales "Evaluation of results" (4\%) and "Flexibility" (3\%), which indicates that they are not critical to their actions, their subjective criteria of success are not sufficiently stable, which leads to a sharp deterioration in the quality of results when an increase in the volume of work, deterioration of the condition or the occurrence of external difficulties, they are also not able to adequately respond to the situation, quickly and timely plan activities and behavior, develop an action program, highlight significant conditions, assess the mismatch of the results obtained for the purpose of activities and make corrections, as a result they inevitably have regulatory failures and, as a result, failures in the performance of their activities.

The data obtained in the course of our research on all scales of the "Style of selfregulation" technique by V.I. Morosanova between humanities students and engineering students, confirm statistically significant differences according to the Student's t-test, where differences are considered significant at $p \geq 0.01-0.05$. The results of the statistical analysis are presented below in Table 2 . 
The data obtained allow us to state that significant differences were diagnosed for almost all scales of the technique. As a result, on the basis of the conducted statistical analysis, it can be concluded that the hypothesis that there are probably differences in the functioning of self-regulation mechanisms among students of different professional orientation has been fully confirmed.

Table 2. Results of statistically significant differences between the averaged data on the scales of the "Style of self-regulation" method by V.I. Morosanova among humanities and engineering students

\begin{tabular}{|l|l|l|l|}
\hline Scales & $\begin{array}{l}\text { Humanities } \\
\text { students }\end{array}$ & $\begin{array}{l}\text { Engineering } \\
\text { students }\end{array}$ & $\begin{array}{l}\text { significance level (p- } \\
\text { value) }\end{array}$ \\
\hline Planning & 5.1 & 8.2 & 0.0264 \\
\hline Modeling & 5.3 & 8.7 & 0.0381 \\
\hline Programming & 7.9 & 6.3 & 0.0486 \\
\hline Evaluating Results & 8.4 & 3.4 & 0.0764 \\
\hline Flexibility & 7.3 & 2.7 & 0.0115 \\
\hline Independence & 6.3 & 7.6 & 0.0622 \\
\hline $\begin{array}{l}\text { General level of self- } \\
\text { regulation }\end{array}$ & 37.8 & 20.1 & 0.0395 \\
\hline
\end{tabular}

Further, we investigated the specificity of volitional regulation by the method of A.V. Zverkova, E.V. Eidman. The data obtained among the entire group of respondents are presented below in Figure 4.

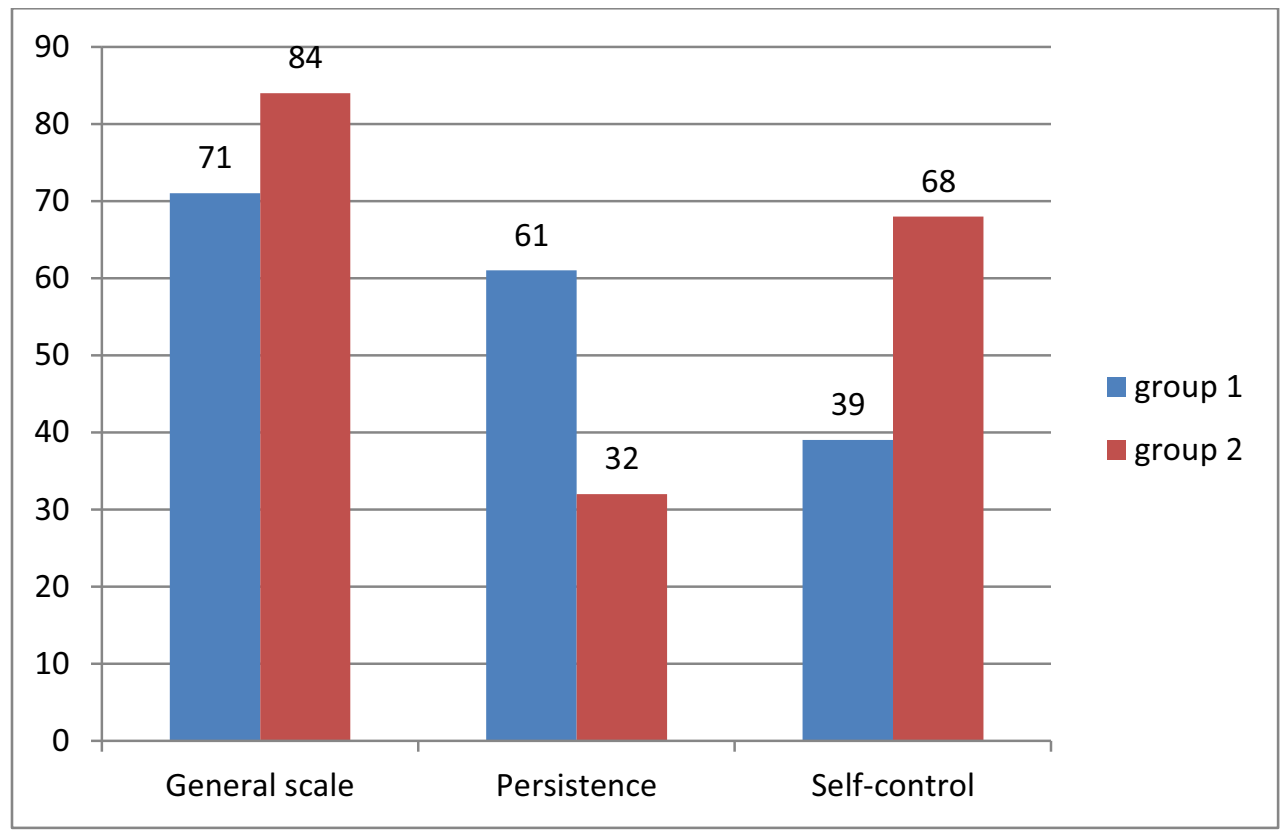

Fig. 4. The severity of the specificity of volitional regulation among the entire sample of students (\%)

Analyzing the results obtained, we can conclude that among the entire sample of respondents, the general level of volitional self-regulation is at a fairly high level among the two groups of respondents. A high level of volitional regulation allows to master our own behavior in various situations, the ability to consciously control our actions, states and impulses. 
However, among the group of humanitarians (group 1), "Perseverance" prevails as a specific feature - 61\% over "Self-control" - 39\%, which characterizes them as selfconfident, possessing stability of intentions, realistic views, and a developed sense of their own duty. As a rule, they are able to reflect well their personal motives, systematically realize the intentions that have arisen, distribute efforts, and are also able to control their actions and have a pronounced socially positive orientation.

Among the group of engineers (group 2), the predominant one is "Self-control" - 68\%, compared with the scale "Persistence" - 36\%, which reflects the level of voluntary control of emotional reactions and states in this group of respondents. They are characterized by inner calmness, which increases the readiness to perceive the new, the unexpected, and, as a rule, is combined with freedom of opinion, a tendency towards innovation and radicalism. At the same time, the desire for constant self-control, excessive deliberate limitation of spontaneity can lead to an increase in internal tension, the prevalence of constant concern and fatigue among this group of respondents.

The data obtained allow us to state that significant differences were diagnosed for all scales of the technique. The results are shown below in Table 3.

Table 3. Results of statistically significant differences between the averaged data on the scales of the methodology "Specificity of volitional regulation" by the method of A.V. Zverkova, E.V. Eidman among humanities and engineering students

\begin{tabular}{|l|l|l|l|}
\hline Scales & $\begin{array}{l}\text { Humanities } \\
\text { students }\end{array}$ & $\begin{array}{l}\text { Engineering } \\
\text { students }\end{array}$ & $\begin{array}{l}\text { significance level (p- } \\
\text { value) }\end{array}$ \\
\hline General scale & 18.1 & 21.3 & 0.0264 \\
\hline Persistence & 13.4 & 10.2 & 0.0381 \\
\hline Self-control & 8.6 & 12.1 & 0.0486 \\
\hline
\end{tabular}

As a result, on the basis of the conducted statistical analysis, it can be concluded that the hypothesis that there may be differences in the functioning of self-regulation mechanisms among students of different professional orientation has been fully confirmed.

\section{Conclusion}

1. We can conclude that among students-humanities, external LC prevails, on the basis of which they tend to rely on their experience, qualifications, competence and level of abilities when achieving the desired result of purposeful activity and initiative. They are characterized by higher cognitive activity, which allows them to encompass past and present events to predict future behavior strategies. Their behavior is characterized by the gradual achievement of success, by improving skills and detailed processing of information coming from outside, as well as the gradual formation of tasks in terms of their complexity. Although, they have less resistance to stress in situations of serious failure, according to J. Rotter.

2. Among the students-engineering of group 2, the internal locus of control prevails, they are characterized by externally directed defensive behavior, in any situation they expect to have a chance of success, but they also pay tribute to the factors that are not dependent on them. They treat the failures lightly and do not take them personally. Often, they need support and approval, perceiving them as happening by themselves.

3. Low values in 2 groups of students were achieved by indicators on the Iz scale $(12 \%$ humanities and $18 \%$ - engineering), which emphasizes the general tendency to low control of their own health.

4. The data obtained in the course of our research on all scales of the "Style of selfregulation" technique by V.I. Morosanova between humanities students and engineering 
students, confirm statistically significant differences according to the Student's t-test, where differences are considered significant at $\mathrm{p} \geq 0.01-0.05$.

5. Among the group of engineers, the predominant one is "Self-control" - 68\%, compared with the scale "Persistence" - 36\%, which reflects the level of voluntary control of emotional reactions and states in this group of respondents. They are characterized by inner calmness, which increases the readiness to perceive the new, the unexpected, and, as a rule, is combined with freedom of opinion, a tendency towards innovation and radicalism. At the same time, the desire for constant self-control, excessive deliberate limitation of spontaneity can lead to an increase in internal tension, the prevalence of constant concern and fatigue among this group of respondents.

As a result, on the basis of the conducted statistical analysis, it can be concluded that the hypothesis that there may be differences in the functioning of self-regulation mechanisms among students of different professional orientation has been fully confirmed.

\section{References}

1. A. Siibak, Reflections of RL in The Virtual World. Cyberpsychology: Journal of Psychosocial Research on Cyberspace (2019) http://cyberpsychology.eu/view.php?cisloclanku $\quad=2007072301 \&$ article $=1 \quad$ (Last accessed 11.07.2020)

2. A. V. Voshchinin, Reflexive regulation of mental states of athletes. Scientific Notes of the University. P.F. Lesgaft, 6(136), 214-217 (2016)

3. E. Rasskazova, Psychological self-regulation as factor of success in the management of own behavior in different life domains. Experimental Psychology, 12(3), 148-163 (2019)

4. E. Pearson, Making a Good (Virtual) First Impression: The Use of Visuals in Online Impression Management and Creating Identity Performances (2019) https://hal.inria.fr/hal-01058173/document (Last accessed 11.07.2020)

5. E. Vorobyeva, V. V. Kosonogov, E. M. Kovsh, P. N. Ermakov, I. Abakumova, Yu. I. Motalova, Overcoming the barriers against learning which are rooted in different understanding of the emotional expression in people of russian and armenian ethnic identities. INTED2019 13th International Technology, Education and Development Conference Conference proceedings. 5958-5963 (2019)

6. E. Vasina, Self-Presentation of an individual in the network: features of language games. https://e.mail.ru/attachment/14819675240000000722/0;1 (23.06.2020)

7. G. Ozhiganova, Self-regulation and self-regulatory capacities: components, levels, models (2018) URL: https://cyberleninka.ru/article/n/self-regulation-and-selfregulatory-capacities-components-levels-models (Last accessed 14.07.2020)

8. I. V. Abakumova, I. A. Bakaeva, K. Y. Kolesina, Technologies of initiating students into independent (self-guided) activity in supplementary distance learning. International Journal of Cognitive Research in Science, Engineering and Education (2016).

9. I. V. Abakumova, P. N. Ermakov, M. V. Godunov, Polar meaning-building strategies: Acmeological characteristics. Psychology in Russia: State of the Art. (2018)

10. M. A. Erofeeva, A. A. Fedorov, Production and consumption of images in the digital age. (2019) http://cyberleninka.ru/article/n/proizvodstvo-i-potreblenie-izobrazheniy-vtsifrovuyu-epohu (Last accessed 16.07.2020)

11. v_obshenii.pdf (2019) (Last accessed 16.07.2020) 
12. O. A. Grimov, Self-presentation and self-identification of a person in social networks (2019) http://www.rusnauka.com/6_PNI_2013/Psihologia/12_129127.doc.htm (Last accessed 16.07.2020)

13. O. V. Shuster, Visuality as a global trend in the space of mass media. http://www.erjournal.ru/journals_n/1375549519.pdf(2019)

14. S. Diefenbach, L. Christoforakos, The Selfie Paradox: Nobody Seems to Like Them Yet Everyone Has Reasons to Take Them. An Exploration of Psychological Functions of Selfies in Self-Presentation. http://journal.frontiersin.org/article/10.3389/fpsyg.2019. 00007/full\#h8 (2019)

15. V. P. Daniel, The Effect of perceived locus jf control and psycological stress on intuitive problem solving. Diss. Abstr. Intern. 37(1), 456 (1976)

16. Yu. O. Obukhova, Mobile phone as a means of self-presentation in interpersonal communication. Journal of sociology and social anthropology. 2,119-138 (2011)

17. V. I. Morosanova, I. N. Bondarenko, A. M. Potanina, Conscious self-regulation as a resource for success in the Russian language in students with different levels of intelligence. Experimental Psychology, 13(1), 63-787 (2020) DOI: 10.17759/exppsy.2020130105 